\title{
INOVANDO A EDUCAÇÃO CORPORATIVA COM MICROLEARNING E GAMIFICAÇÃO
}

\author{
SALVADOR/BA JULHO/2018
}

\author{
Marcelle Rose da Silva Minho - SENAI BAHIA - marcelle.minho@gmail.com \\ Thais Araújo Soares - SENAI BAHIA - thaisaraujo.s@hotmail.com \\ Victor de Morais Cayres - SENAI BAHIA - victorcayres@gmail.com \\ Igor Nogueira Oliveira Dantas - SENAI BAHIA - noudant@gmail.com \\ Sergio Eduardo Cristofoletti - STARRETT - cristo@starrett.com.br \\ Ricardo Santos Lima - SENAI BAHIA - rlima@fieb.org.br \\ Luis Aberto Breda Mascarenhas - SENAI BAHIA - breda@fieb.org.br
}

Tipo: Relato de Experiência Inovadora (EI)

Categoria: Métodos e Tecnologias

Setor Educacional: EDUCAÇÃO CORPORATIVA

\begin{abstract}
RESUMO
Este artigo relata o processo de desenvolvimento do programa de educação corporativa da Starrett, como uma possível solução às demandas contemporâneas de capacitação empresarial aliada às tecnologias digitais. A proposta do programa foi concebida baseada no perfil dos usuários e fundamentada no conceito do microlearning aliado a estratégias de gamificação, tendo como princípios norteadores a aprendizagem por meio do desenvolvimento de competências, a interação e 0 engajamento por parte dos usuários. A etapa de desenvolvimento foi concluída com a realização de um piloto com o primeiro módulo do programa e a avaliação dos dados levantados forneceram material para o amadurecimento do sistema para os demais módulos.
\end{abstract}

Palavras-chave: Microlearning, Gamificação, Educação Corporativa, Inovação Educacional 


\section{INTRODUÇÃO}

Diante do cenário atual, em que a quantidade de informação disponível, a velocidade da renovação de conteúdos e a inovação tecnológica são constantes, percebe-se a necessidade de novas estratégias de disseminação do conhecimento por parte das empresas, que se reflete em programas de capacitação corporativa inovadores. Mas, qual a melhor estratégia para conceber um programa que atenda as necessidades específicas das empresas?

A Starrett buscou ferramentas comercialmente disponíveis para atender a sua demanda no compartilhamento do conhecimento associado aos seus produtos. Entretanto, mesmo com toda expertise, percebeu-se que capacitar uma grande quantidade de vendedores, em uma grande linha de produtos, em tempo recorde, não seria possível utilizando metodologias tradicionais.

A partir de uma parceria com o Senai-Bahia, a Starrett conseguiu apoio técnicopedagógico especializado para a concepção de um programa de treinamento corporativo exclusivo, que atendesse não somente à sua demanda, mas principalmente às necessidades do público-alvo.

Por meio de discussões e reflexões sobre os objetivos e as necessidades da empresa e o perfil do usuário, o Senai-Bahia propôs um programa de educação corporativa denominado como Venda Mais Starrett. Esse programa tem como premissa o desenvolvimento das capacidades técnicas de representantes comerciais que vendem os produtos da Starrett, oportunizando a disseminação do conhecimento e promovendo seu crescimento técnico no exercício da sua profissão.

Este estudo reúne relatos do processo de desenvolvimento do programa inovador de educação corporativa da Starrett, que foi baseado na utilização do microlearning e da gamificação. A seguir, serão relatadas as premissas metodológicas e as etapas de desenvolvimento do Venda Mais Starrett.

\section{PERSPECTIVAS TEÓRICAS}

Por tratar-se de uma formação no âmbito da educação profissional, a abordagem baseada em competência se configura como mais indicada uma vez que articula os conhecimentos e habilidades do sujeito para resolver determinada situação complexa (PERRENOUD, 1999). Trata-se de uma abordagem onde a contextualização na prática assume papel de destaque no Design Educacional, possibilitando uma aprendizagem 
mais significativa.

Em 2016, segundo o IBGE, 92,3\% dos domicílios brasileiros possuíam celular e 60,3\% deles acessaram a internet por meio deles. De acordo com Souza e Amaral (2002), "as tecnologias móveis, como o celular e o tablet, trazem um leque de oportunidades para a criação de novos espaços voltados a práticas educacionais mediadas pelas linguagens híbridas (...)", que podem favorecer os resultados dos treinamentos corporativos.

Considerando este cenário, o microlearning surge como uma modalidade de aprendizagem adequada a esta demanda. Para Gabrielli et al. (2006 apud SOUZA E AMARAL, 2002, p. 4), o microlearning "baseia-se na ideia de desenvolvimento de pequenos pedaços de conteúdo [...] e no uso de tecnologias flexíveis que permitam aos alunos acessá-los mais facilmente em momentos específicos [...]", podendo, ser conceituado como uma técnica de ensino-aprendizagem rápida e concisa por meio de tecnologias da informação e comunicação.

O microlearning, aliado à formação por competência, pode promover uma aprendizagem significativa demandando menor tempo de preparação, tendo como exemplo as pílulas do conhecimento. Diferente das metodologias convencionais, de acordo com Santaella (2011 apud SOUZA E AMARAL, 2002, p. 8), as pílulas configuram-se em uma maneira prática e dinâmica de apresentar os conteúdos a partir de diversos recursos da hipermídia. Com foco no processo de ensino aprendizagem ativo e na disponibilidade de tempo dos partícipes, as pílulas oferecem pequenas quantidades de informação organizada de forma criativa, por meio de mídias como vídeos, animações e cards. Através dessa metodologia, o usuário pode buscar o conhecimento de forma proativa, no momento em que necessitar, deixando de lado a costumeira postura passiva adotada pelo ensino tradicional. Há ainda outras vantagens na utilização desta modalidade, como o aprendizado focado, a facilidade de acesso às informações devido à utilização de dispositivos móveis e minimização do tempo utilizado. Contudo, é evidente que não se trata de uma alternativa que atenda a qualquer demanda educacional.

Para potencializar os benefícios do microlearning, este foi associada à uma estratégia de gamificação. Em 2011, Deterding, Dixon, Khaled e Nacke (2011) enunciaram gamificação como determinadas práticas lúdicas com metas e resultados quantificáveis, abrangendo os jogos regulamentados e excluindo as brincadeiras, chamando atenção para o processo de projetar um jogo, ou seja, gamificar não é apenas utilizar elementos dos jogos, mas utilizar padrões, mecânicas, princípios, heurísticas e modelos do design de jogos. Já Werbach (2014) propõe uma definição que põe ênfase no processo. Para o autor, essa perspectiva foca a atenção na criação de experiências mais próximas dos 
games e cria uma maior integração entre as perspectivas da academia e do Mercado. Para o autor, a ênfase na concepção da experiência é mais estimulante no sentido de expandir as possibilidades de criação ao invés de dar o seu trabalho como encerrado ao simplesmente utilizar elementos de games em um outro contexto. Neste trabalho, optouse pela definição de gamificação de Werbach (2014), já que o foco é na experiência e no engajamento que alcança-se ao tornar algo mais próximo dos games do que propriamente o uso de elementos de game design. Para o desenvolvimento do programa, os fundamentos do design de interação serviram de base, focados na abordagem centrada no usuário, que visa conhecer suas necessidades e desejos, compreendendo "o que", "por quê" e "como" antes de projetá-la. (ROGERS; SHARP; PREECE, 2013).

\section{PROCESSO DE DESENVOLVIMENTO}

Seguindo os fundamentos do design de interação, antes de projetar a aplicação, foi feito um mapeamento do público-alvo no sentido de entender suas necessidades e aspirações. A partir de visitas in loco, entrevistas com os usuários finais e seus empregadores, foi possível construir um perfil deste público, que norteou a concepção da aplicação. O perfil desse usuários mostra: pessoas com pouco tempo, altamente competitivas, trabalham de forma autônoma, usam celular como ferramenta de trabalho, possuem clientes de lojas pequenas e familiares, são inseguros para ampliar o portfólio porque têm medo de oferecer produtos novos e caros e precisam ter tudo à mão (catálogos, lista de preço, argumentos).

Nesse contexto, foi necessário conceber uma solução educacional que fosse capaz de envolver os usuários, focada na realidade deles, que demandasse pouco tempo de dedicação diária e possibilitasse ganhos reais no desempenho da sua função.

Antes de iniciar o desenvolvimento, foi feito um protótipo de baixa fidelidade com o objetivo de validar o design educacional. Este protótipo foi utilizado por dois usuários que afirmaram ter se sentido estimulados e sinalizaram ter compreendido bem as perguntas, destacando que este programa seria muito útil para eles no dia a dia, sanando dúvidas sobre características dos produtos.

Dessa forma, com base na análise criteriosa do perfil do público alvo, o Venda Mais Starrett foi concebido como um modelo educacional baseado no microlearning e na gamificação, tendo como pilares principais: a) a aprendizagem, com foco no desenvolvimento de competências; b) a interação, que fomenta o compartilhamento de conhecimento e a troca de experiências c) o engajamento, com foco no estímulo à 
participação.

Entendemos que a gamificação atua como potencializadora da participação, autossuperação e cooperação entre os usuários, permitindo o acompanhamento de seu desempenho em tempo real. Já o microlearning apresenta contextos práticos, focados na resolução de problemas. A associação dessas estratégias, portanto, mostrava-se plenamente aplicável.

No planejamento educacional, foram definidas a competência geral e as capacidades associadas, criadas para atender todos os aspectos relacionados aos produtos e aos comportamentos dos representantes quanto ao relacionamento deles com os clientes e o mercado em geral. Fundamentado nessa concepção, foi pensado um design educacional que inovou a forma de apresentar o conteúdo, alterando o formato tradicional do e-learning e criando um processo baseado em perguntas com feedbacks educativos. Cada pergunta foi baseada em um contexto prático, com impacto direto em cada capacidade a ser aprendida. Foi concebido, então, um conjunto de três perguntas, cada uma com seu feedback respectivo, que estão associadas a uma capacidade, que por sua vez também tem seu próprio feedback. Ou seja, ao errar uma questão do grupo de três, o usuário recebe o feedback da questão informando que se equivocou e, ao terminar o bloco de três perguntas, recebe outro feedback, que pode ser positivo, ao acertar todas as questões, ou negativo, ao errar ao menos uma, conforme pode ser observado a seguir:

Figura 1 - Telas do Venda Mais Starrett
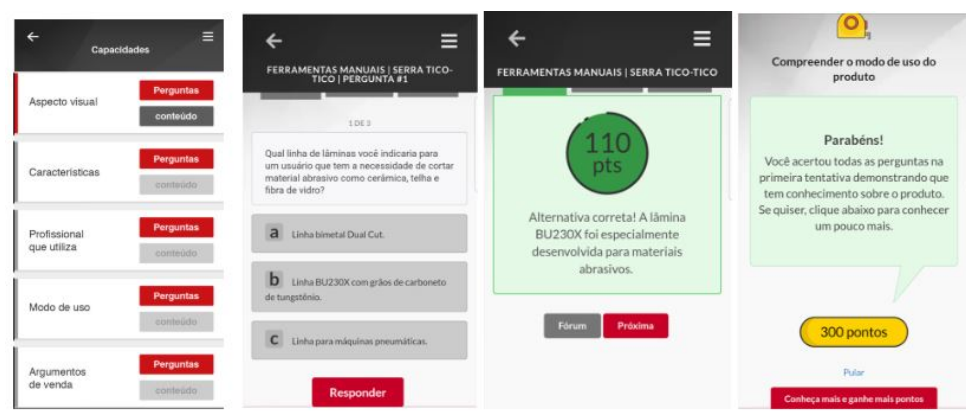

Em cada pergunta, o usuário pode acessar o fórum e discutir a questão proposta. Ao terminar o bloco de questões, o usuário pode ser direcionado à pílula do conhecimento, onde são apresentados os conteúdos, de forma dinâmica, podendo ser em forma de vídeo, animação ou card. As pílulas são apresentadas ao usuário obrigatoriamente, em caso de haver alguma resposta errada e, facultativamente, em caso de acerto de todas as perguntas. Dessa forma, além de valorizar o conhecimento prévio do aluno, esse design educacional viabiliza a aquisição de novos conhecimentos e a aplicação prática 
do conteúdo aprendido. Além disso, permite que o programa seja realizado com dedicação diária de apenas 15 minutos, se adequando à rotina do usuário.

O conteúdo foi escrito por técnicos e engenheiros dentro do formato de perguntas e respostas, passando pela análise do designer educacional. Para definir a estratégia de gamificação aplicada no Venda Mais Starrett, foi utilizado um framework voltado para a concepção de estratégias de gamificação já validado em outros processos e publicado em um trabalho anterior (CAYRES; MINHO; LIMA; MASCARENHAS, 2018). Trabalhouse com os objetivos definidos e foi elicitado, a partir deles, comportamentos esperados dos usuários que podiam ser estimulados através da gamificação. Definiu-se, também, mecânicas e dinâmicas do jogo que pudessem estimular tais comportamentos de forma alinhada com o perfil do público-alvo e da estratégia educacional adotada. A pesquisa com o público-alvo, no que diz respeito à gamificação, mostrou um perfil de usuário competitivo e que dispunha de pouco tempo para aprender mais sobre os produtos que vendia. Adotou-se então uma abordagem competitiva para a estratégia de gamificação, concretizando-a em um ranking baseado em pontos, que pode ser visualizado no ranking geral, por região do Brasil ou por empresa. Os comportamentos foram a base para definir mecânicas e as dinâmicas de interação com o sistema. Também determinouse quais das ações possíveis são valorizadas através de recompensas, nesse caso, pontos, badges e power ups. Os pontos são quantificações do valor de cada ação no sistema. O termo power up, nos jogos eletrônicos, designa itens ou objetos que dão algum tipo de poder ou vantagem no jogo. No caso do Venda Mais Starrett, fornecem ao usuário um fator de multiplicação dos pontos quando são realizadas ações mais desafiadoras. Por fim, as badges, apresentadas no programa como selos, representam conquistas significativas no sistema, feitos memoráveis.

Para a elaboração da interface do produto, foi utilizado o conceito do mobile first, que se caracteriza pela concepção de projetos web priorizando a arquitetura e o desenvolvimento para dispositivos móveis, além de ter como premissa o manual de identidade visual da Starrett que estabelece todas as diretrizes com relação à aplicação de cores e tipografia. Com relação ao desenvolvimento do sistema, foi utilizado um framework de código aberto para produção de aplicações web baseado na linguagem PHP e que traz uma maior produtividade no desenvolvimento de sistemas em três camadas (MVC). Usou-se também o CSS para diagramação dos leiautes, gerando responsividade para os diferentes tamanhos de tela, e o JavaScript para animações e interações na camada do cliente.

\section{PILOTO}


Ao longo do desenvolvimento, foram realizados testes internos com a finalidade de validar a interface, elementos visuais e as funcionalidades do sistema. Com a versão Beta pronta, foi realizado um piloto com 24 colaboradores da Starrett com o intuito identificar oportunidades de melhorias, antes do programa ser disponibilizado para o público final. Foi utilizado um questionário estruturado em 05 partes: identificação do perfil, experiência como usuário, aprendizagem, compreensão do sistema e percepções e sugestões, utilizando perguntas de múltiplas escolha e a escala Likert, que especifica o nível de concordância de uma afirmação a partir de uma graduação em cinco níveis. $O$ instrumento foi respondido por 12 pessoas, cujo perfil é possível verificar na imagem a seguir.

Figura 2 - Representação do usuário

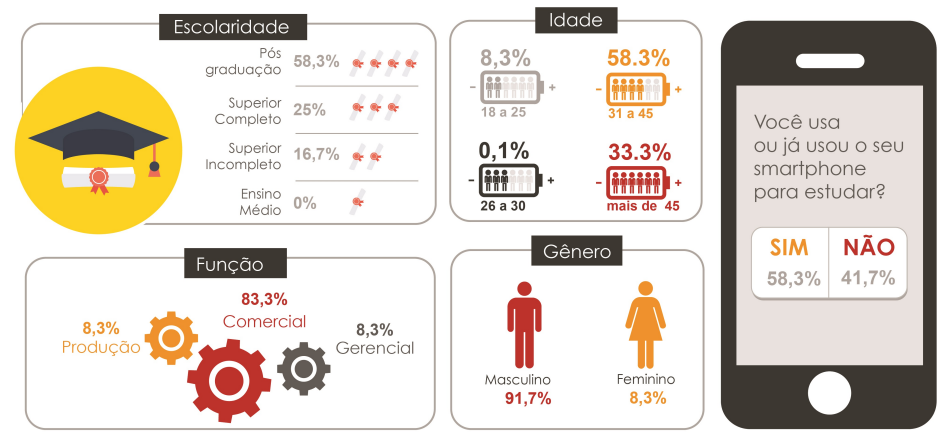

Verificamos que a maioria são: homens (91,7\%), possuem idade entre 31 e 45 anos $(58,3 \%)$, são pós-graduados $(58,3 \%)$, atuam na equipe comercial $(83,3 \%)$ e já utilizaram o celular para estudar (58,3\%).

A parte sobre a experiência como usuário foi realizada com base no GameFlow, um modelo voltado para a avaliação de jogos, proposto por Penelope Sweester e Peta Wyeth, que se baseia na ideia de experiência ótima, teoria do fluxo do psicólogo húngaro Mihaly Csikszentmihalyi (2002). Conforme a imagem abaixo, percebe-se a obtenção de um resultado satisfatório em relação à experiência no Venda Mais Starrett, com destaque para os itens clareza de objetivo e elementos que chamam atenção. A concentração enquanto estudava foi o item menos pontuado, sendo a lentidão da exibição dos vídeos um fator que pode ter influenciado neste aspecto, uma vez que foi muito apontado na parte de percepções e sugestões do questionário. Vale ressaltar também o feedback positivo em relação à crescente habilidade para interagir com o sistema, validando a usabilidade do programa.

Figura 3 - Relato de experiência 


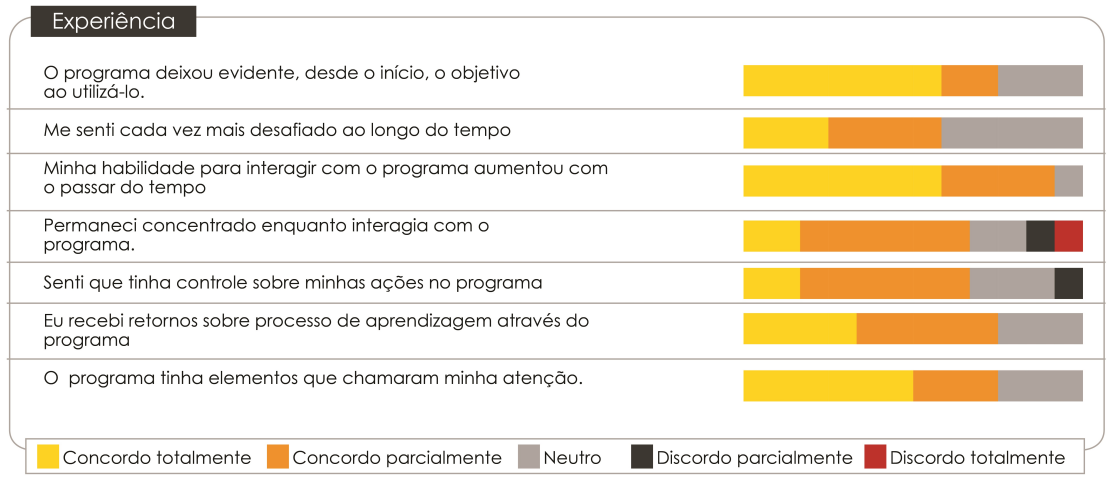

No tocante à aprendizagem, percebe-se que todos os usuários entendem que ampliaram os conhecimentos com o Venda Mais Starrett e que as informações estavam claras, objetivas, são relevantes para o dia a dia e melhoram seus argumentos de vendas.

Figura 4 - Relato de aprendizagem

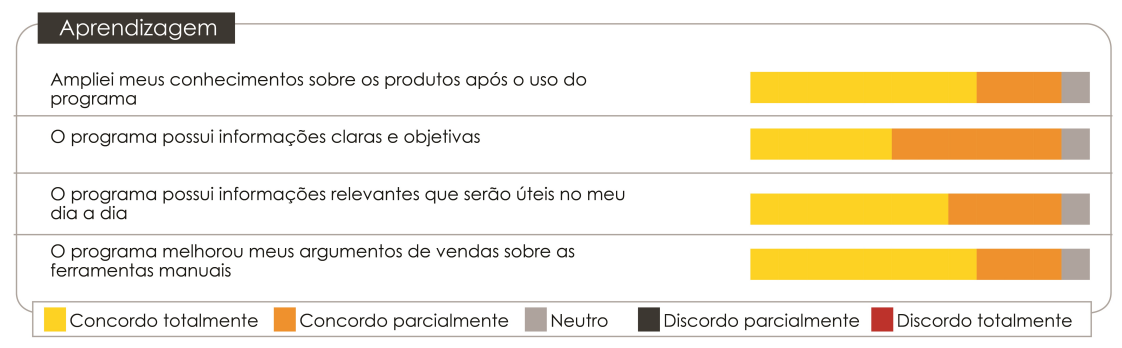

A parte de compreensão do sistema foi estruturada de forma a perceber o nível de entendimento dos usuários em relação à estratégia de gamificação. Na imagem abaixo, fica evidente que as condições para o alcance dos selos de expert e de qualificado não ficaram claras, visto que a maioria afirmou não perceber esta regra. O multiplicador de pontos por dias consecutivos de uso também não foi percebido, e o fato de os usuários terem finalizado o programa em apenas dois dias pode ter sido preponderante para sua inobservância.

Figura 5 - Relato de compreensão do sistema

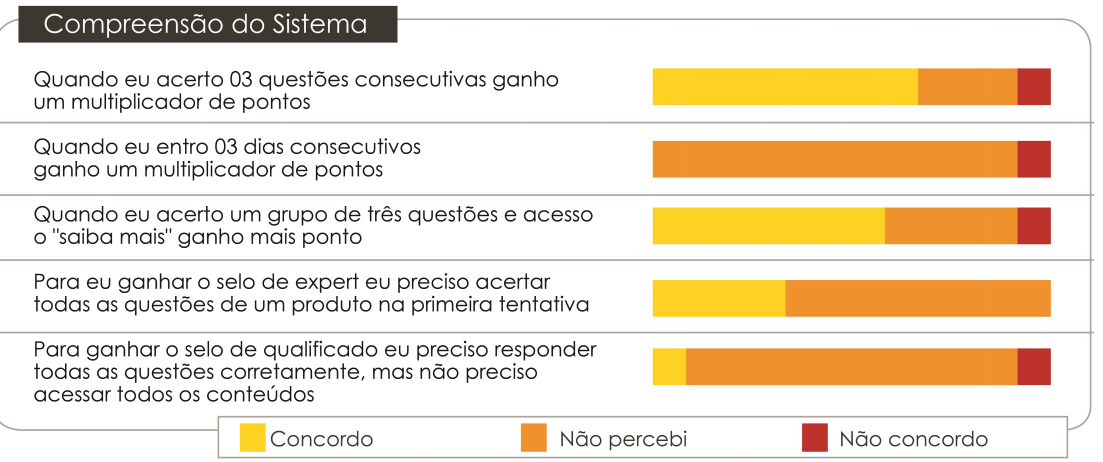


A última parte do questionário forneceu informações sobre as percepções e sugestões dos usuários sobre o Venda Mais Starrett. Em relação ao nível de satisfação, 80\% afirmaram que o programa atendeu às expectativas e $20 \%$ que as superou. A lentidão do sistema foi apontada em 6 dos 12 questionários respondidos. Em relação ao que mais agradou, as pílulas do conhecimento, as informações e a objetividade foram os aspectos mais citados.

\section{CONSIDERAÇÕES FINAIS}

A estratégia de unir microlearning e gamificação resultou em um produto inovador, que atendeu às necessidades de disseminação do conhecimento com alto índice de satisfação, conforme apontou o piloto. A etapa de mapeamento do público-alvo foi fundamental para o alcance dos resultados evidenciados, o que demonstrou também oportunidades de melhorias importantes como a otimização das mídias para melhor desempenho do programa e detalhamento das regras para alcance dos selos, que serão implementadas para a utilização do público final.

Entende-se como limitação deste estudo que, apesar de o processo de desenvolvimento ter sido baseado no perfil do usuário final, o piloto não foi realizado com este público, mas sim com colaboradores da empresa, sendo que ambos são profissionais da área de vendas, com a diferença que o público-alvo é representante autônomo. Dessa forma, essa diferença entre estes públicos pode impactar na precisão de um resultado mais específico com relação ao desempenho do projeto.

Espera-se, portanto, nas próximas publicações relatar os resultados alcançados com os usuários finais, investigando a relação entre o desempenho no programa e o impacto na empresa, avaliando a efetividade da estratégia educacional proposta para essa demanda específica.

\section{REFERÊNCIAS}

CAYRES, Victor de M.; MINHO, Marcelle R. da S.; LIMA, Ricardo S.; MASCARENHAS, Luís Alberto B. Uma viagem para o futuro: os caminhos da concepção de uma estratégia gamificada para o ensino profissionalizante do Senai DR-Ba. Anais... Play2Learn. The Gamilearning Conference. Lisboa, 2018.

DETERDING, Sebastian et al. From game design elements to gamefulness: defining, Gamification". In: Proceedings of the 15th International Academic MindTrek Conference: envisioning future media environments. New York, USA: ACM, 2011. $p$. 
9-15.

INSTITUTO BRASILEIRO DE GEOGRAFIA E ESTATÍSTICA (IBGE). PNAD 2016: elederly population grows $16.0 \%$ over 2012 and reaches 29.6 million. 2017. Disponível em:

$<$ https://agenciadenoticias.ibge.gov.br/en/2185-news-agency/releases-en/18328-pnad-2 016-elederly-population-grows-16-0-over-2012-and-reaches-29-6-million.html>. Acesso em: 18 maio 2018.

SOUZA, Márcia Izabel Fugisawa; AMARAL, Sérgio Ferreira do. Microconteúdo para ambiente virtual de aprendizagem Móvel: modelo de produção baseado nas matrizes da linguagem e pensamento. In: CONGRESSO BRASILEIRO DE CIÊNCIAS DA COMUNICAÇÃO, 35., Fortaleza, 2012. Anais... Fortaleza: Intercom, 2012. Disponível em: $<$ http://www.intercom.org.br/sis/2012/resumos/R7-1075-1.pdf>. Acesso em: 17 maio 2018.

PERRENOUD, Philippe. Construir as competências desde a escola. Porto Alegre: Artmed, 1999.

ROGERS, Yvonne; SHARP, Helen; PREECE, Jennifer. Design de interação: além da interação humano-computador. 3. ed. Porto Alegre: Bookman, 2013.

SERVIÇO NACIONAL DE APRENDIZAGEM INDUSTRIAL. Departamento Nacional. Metodologia SENAI de educação profissional. Brasília: SENAI/DN, 2013.

SWEETSER, Penelope; WYETH, Peta. GameFlow: a model for evaluating player enjoyment in games.Computers in Entertainment, n.3, v.3, p. 1-24, july, 2005.

WERBACH, Kevin. (Re)Defining Gamification: a process approach. Lecture notes in computer science, Springer, v. 8462, 2014. p. 266-272. Disponível em: $<$ https://link.springer.com/chapter/10.1007/978-3-319-07127-5_23>. Acesso em: 18 maio 2018. 